\title{
¿Cómo las obras literarias atraviesan fronteras (o no)? Una aproximación sociológica a la literatura mundial ${ }^{1}$
}

\author{
GISÈLE SAPIRO CNRS / École des Hautes Études en Sciences Sociales, Francia / sapiro@ehess.fr / \\ Traducción de Analía Gerbaudo y Santiago Venturini / Universidad Nacional del Litoral - CONICET, Argentina / \\ analia.gerbaudo@conicet.gov.ar/venturini.santiago@gmail.com
}

\section{Resumen}

Este artículo analiza los factores que fomentan o dificultan la circulación de la literatura más allá de sus fronteras geográficas y culturales, es decir, de los que participan en los mecanismos de producción de la literatura mundial. A los efectos del análisis, estos factores pueden clasificarse en cuatro categorías: políticos (o más ampliamente, ideológicos), económicos, culturales y sociales. Materializados en instituciones y en agentes individuales, estos factores pueden reforzarse o contradecirse entre sí causando, por lo tanto, tensiones y luchas. El artículo concluye con reflexiones sobre las dos tendencias opuestas que caracterizan al campo literario transnacional: isomorfismo y lógicas diferenciales.

Palabras clave: literatura mundial / sociología de la literatura / sociología de la traducción / circulación internacional de la literatura / campo teórico

Para citar este artículo: Sapiro, Gisèle (2018). «¿Cómo las obras literarias atraviesan fronteras (o no)? Una aproximación sociológica a la literatura mundial». El taco en la brea 7 (diciembre-mayo), 182-194 Santa Fe, Argentina: UNL. DOI: https://doi.org/10.14409/tb.voi7.7363 
Si consideramos que la literatura mundial refiere a las obras literarias que circulan más allá de sus fronteras nacionales (Damrosch), entonces debemos preguntarnos cómo estas obras circulan y qué obstáculos encuentran (Apter). Estos obstáculos no son sólo lingüísticos; hay tanto obstáculos sociales como hay factores sociales que provocan la circulación de los textos sin tener en cuenta su valor intrínseco. Por lo tanto, se requiere una aproximación sociológica para identificar estos factores y los mecanismos de producción de la literatura mundial, además de sus jerarquías específicas (Casanova).

En un artículo seminal sobre «las condiciones sociales de la circulación de las ideas», Pierre Bourdieu delineó un programa para estudiar las estrategias elaboradas por individuos o grupos involucrados en este proceso (Bourdieu «Las condiciones sociales»). Este enfoque se deriva del postulado de que las ideas no se propagan mecánicamente por contagio espiritual (Tarde) sino que están atravesadas por medios materiales como libros, diarios, revistas e internet, o por la difusión oral en escenarios públicos o privados. Por consiguiente, la sociología de los intercambios culturales transnacionales se ha centrado en los agentes - individuos, grupos, institucionesque participan en esta circulación: autores, editores, representantes del Estado, agentes literarios, traductores y críticos, en el caso de obras literarias (Heilbron y Sapiro). Basada en diferentes fuentes (Index Translationum de la UNESCO, bibliografías nacionales, base de datos de librerías profesionales, catálogos editoriales, listas establecidas por representantes estatales), la construcción de bases de datos de obras traducidas en distintas lenguas ha suministrado material para estadísticas de flujos. La aplicación del sistema mundial de análisis para los flujos de libros traducidos en diferentes lenguas (Heilbron), países (Popa) y ciudades (Sapiro «Globalization») ha constatado las asimetrías de los intercambios entre centros y periferias. Estas bases de datos son también una rica fuente para el estudio de qué se traduce de una lengua a otra, y por quién (Popa; Sapiro Translatio; Sapiro «Symbolic Capital»). Dichos datos cuantitativos visualizan patrones y regularidades que nos ayudan a entender los factores que pueden obstaculizar o fomentar la circulación de bienes simbólicos en un contexto particular, y plantean la cuestión de las motivaciones de los mediadores. Las hipótesis pueden confirmarse o revisarse a la luz de datos cualitativos como (auto)biografías y memorias, archivos, entrevistas, recepción crítica en los medios y en eventos culturales tales como ferias de libros, festivales y premios literarios.

Estos factores pueden dividirse, a los efectos del análisis, en cuatro categorías: factores políticos, económicos, culturales y sociales. Los investigadores en literatura y los especialistas en estudios de traducción, por lo general, se centran en los factores culturales y en los textos. Los historiadores que trabajan en transferencias culturales han tenido en cuenta los factores políticos así como el rol de los actores, pero han desatendido los aspectos económicos, mientras que los historiadores de la edición, hasta hace poco, le prestaban poca atención a la cuestión de la traducción. Los factores sociales fueron identificados principalmente en los estudios poscoloniales, de género y por sociólogos de la cultura. En la mayor parte de los casos, estos cuatro tipos de factores están integrados, pero en algunos contextos, un tipo puede prevalecer y subordinar a los otros. Los presentaré aquí por separado, proporcionando ejemplos de cada uno, con el fin de proponer un marco de análisis de las condiciones sociales de circulación de las obras literarias. En la conclusión discutiré algunas cuestiones teóricas sobre dinámicas sociohistóricas: mientras las transferencias culturales pueden, en parte, describirse en términos de isomorfismo - ya sea por imitación, coacciones o normas compartidas, tal como ha analizado la teoría neo-institucional 
(DiMaggio y Powell) - explicar estas transferencias también requiere que se introduzcan las lógicas de diferenciación. La combinación de estos dos procesos provee un marco explicativo para los dos modelos evolutivos señalados por Franco Moretti: ondas y árboles.

\section{Factores políticos}

Los factores políticos y, más ampliamente, los ideológicos, fomentan o dificultan la circulación de los textos literarios. La traducción puede servir a propósitos políticos o ideológicos: puede ser un medio para diseminar una doctrina o una visión del mundo. Los partidos y las organizaciones políticas han contribuido a la circulación internacional de obras como la de Marx y Engels, a través de redes más o menos organizadas y de la construcción del canon mundial del realismo socialista. Lenin fue el autor más traducido entre 1955 y 1980 según la base de datos Index Translationum (Venutti:158).

Sin embargo, esta estrategia de diseminación puede ser contrarrestada por medios legales. Los Estados han impuesto fronteras legales mediante el copyright, restricciones a la prensa y control político sobre la circulación de lo impreso que varían de acuerdo al grado de autoritarismo versus liberalismo. Las publicaciones extranjeras a menudo tienen un régimen específico y son sometidas a un control más severo que las publicaciones en la lengua nacional. Por ejemplo, mientras que en 1956 la publicación original de Lolita de Nabokov en inglés en París por Olympia Press fue prohibida por el Ministerio del Interior, Gallimard no tuvo inconvenientes para publicar la traducción al francés tres años después. Esto no puede explicarse sólo por la sulfurosa reputación de Olympia Press comparada con el prestigio de Gallimard. El recrudecimiento del control estatal sobre la edición durante la guerra de Argelia no fue el resultado de la evolución liberal sino la expresión de la desconfianza acumulada respecto de las publicaciones extranjeras. Este ejemplo muestra que la traducción puede ser una vía para eludir la censura. No obstante, el primer intento de publicar el libro original en Francia confirma, además, las dificultades que el autor tuvo que enfrentar en su propio país, los Estados Unidos, menos liberal que Francia. William Burroughs tuvo que afrontar coacciones similares con El almuerzo desnudo: primero publicado en inglés en París por Olympia Press en 1959, su traducción publicada por Gallimard tuvo algunas dificultades con la censura; reeditado en una versión distinta por Grove Press en 1962, fue prohibido por obscenidad en Boston y en Los Ángeles, hasta que la Suprema Corte de Massachusetts revocó la decisión en 1966.

Menos riesgosa que la publicación clandestina (denominada en ruso samiszdat), la publicación en el extranjero, mientras que garantiza una audiencia más amplia, fue una estrategia adoptada por muchos escritores opositores en países con regímenes autoritarios, tanto en la lengua original como en traducción; tal es el caso de Doctor Zhivago de Pasternak, primero publicado en Italia en 1957 por Feltrinelli, o el de las novelas de Milan Kundera, publicadas en traducción francesa antes de emigrar a París (Popa). En países en los que el campo económico está subordinado al campo político y en los que las instituciones que administran la producción cultural tanto como la organización de las profesiones intelectuales son estatales, tanto en regímenes fascistas como comunistas, la producción y la circulación de los bienes simbólicos están sumamente politizadas (Sapiro «Literary Field»; sobre la traducción de libros para niños en la República Democrática Alemana, ver Thomson-Wohlgemuth; sobre las traducciones en la Italia fascista, ver Rundle). Durante la ocupación alemana en Francia, el Tercer Reich prohibió las traducciones del francés al alemán, 
con excepción de un reducido número de escritores que eran activos colaboracionistas. Al mismo tiempo las fuerzas de ocupación alemanas exigieron a los editores franceses traducir tantos autores alemanes como fuera posible, como parte de su política para quebrar la hegemonía cultural francesa: Gallimard publicó, por ejemplo, un par de títulos de Ernst Jünger (Loiseaux:110-111).

La traducción es, en efecto, una cuestión en la que se juegan relaciones de poder entre países, más allá de cualquier consideración política. Para un Estado-Nación, exportar su literatura mediante la traducción es un signo de reconocimiento simbólico en la escena internacional. Por ello muchos Estados conceden apoyo económico a esta exportación. No obstante, las políticas estatales de apoyo a la traducción pueden, en algunas ocasiones, integrarse en una estrategia política más amplia: en Israel, por ejemplo, una de las justificaciones oficiales para la subvención pública destinada al Instituto para la Traducción de la Literatura Hebrea fue que contribuiría a mejorar la imagen del país, internacionalmente censurada por la ocupación de los territorios palestinos (entrevista con el Director del Instituto, 31 de octubre, 2001). Por otro lado, el apoyo estatal para la traducción de obras extranjeras a la lengua propia puede justificarse por metas educativas o científicas como alcanzar cierto nivel o "ponerse al día» respecto de los estándares internacionales, como lo demuestra el caso de los países árabes (Jacquemond).En estos casos, los factores políticos y culturales están interrelacionados. Los factores económicos tal como el apoyo a la industria editorial nacional pueden también ser utilizados como una justificación para una intervención del Estado en favor de la traducción, como sucede actualmente en Francia. Sin embargo, los agentes estatales que impulsaron políticas a favor de las traducciones desde y hacia el francés hacia fines de los años 80, estuvieron orientados por motivaciones más culturales e intentaron contrarrestar los efectos de las lógicas del mercado sobre la circulación internacional de libros, especialmente la reducción de la diversidad cultural y el creciente dominio del inglés.

\section{Factores económicos: las lógicas del mercado}

La circulación de obras en papel depende de las industrias del libro y de la edición y de las redes de distribución. El desarrollo capitalista de la edición dio un fuerte impulso a esta circulación que fue fomentada a finales del siglo XIX, por la industrialización y luego, por el desarrollo de nuevos medios de transporte. La producción del libro se concentró en ciudades como Leipzig, París y Londres que se transformaron en centros culturales de áreas lingüísticas. No obstante, la circulación de libros en dichas áreas depende tanto de la distribución como de las redes de producción. A pesar de una larga tradición de edición concentrada en Beirut y en El Cairo, la carencia de dichas redes todavía limita hoy la circulación de libros en los países de habla árabe. La competencia entre los países también puede impedirla, como lo demuestra el caso latinoamericano: los intentos del gobierno francés para facilitar la coedición de traducciones del francés al español con editoriales de diferentes países latinoamericanos encuentra mucha reticencia (entrevista con un representante francés en Santiago de Chile, marzo de 2008).

El mercado de la publicación, por consiguiente, está estructurado alrededor de dos tipos de fronteras: cultural (lingüística) y política. El cruce de fronteras legales en el interior de la misma área lingüística depende de relaciones de poder político, económico y cultural entre países. Por ejemplo, Hachette International, actualmente una filial del grupo Lagardère, tiene el $85 \%$ de las acciones en el mercado del libro educativo en las antiguas colonias francesas en África donde la industria del libro está poco desarrollada (Perucca; Pinhas). 
El mercado internacional del libro ha estado regulado desde 1886 por el Convenio de Berna para la Protección de las Obras Literarias y Artísticas que requiere que los editores compren los derechos de distribución o de traducción para los libros a su editor o agente literario original durante el período en el que la ley de copyright esté vigente (por lo general, 70 años, aunque la duración varía según los países). La ley de copyright contribuye a la profesionalización de la edición y al establecimiento de normas en el mercado del libro protegiendo del plagio, al mismo tiempo, al autor y al traductor; sin embargo, puede también ser vista como una limitación a la circulación de libros que refuerza el poder de los centros editoriales mientras que muchos editores, en países pobres, no tienen los medios para comprar los derechos (Venuti:161). Al suscribir los derechos morales conforme a la legislación francesa sobre los derechos de autor (droit d'auteur),el Convenio de Berna también garantiza al autor el droit de regard la obra traducida (elección del editor y del traductor, calidad de la traducción, cambios en el texto). Los Estados Unidos nunca suscribieron al Convenio de Berna por esta cláusula sobre derechos morales considerada un obstáculo al libre comercio. Por esta razón, el acuerdo de la WTO de 1994 sobre los Aspectos de los Derechos de Propiedad Intelectual relacionados con el Comercio (TRIPS) elude la cláusula de los derechos morales. En consecuencia, este acuerdo podría desestabilizar la norma de respeto al texto original que ha prevalecido en la edición de calidad desde el Convenio de Berna, pero ese avance es limitado a través del uso de contratos en los que el editor original puede solicitar que no se introduzcan cortes o modificaciones en la obra tanto como negociar el derecho a droit de regard para el autor.

La delimitación de «territorios» en la circulación de libros a través de áreas linguísticas es también un asunto en juego en la negociación de contratos. Los editores tienden a exigir derechos de traducción mundiales, mientras que el editor original intenta dividir los derechos entre dos editores diferentes para la misma lengua quienes anexarán los territorios de distribución a sus contratos (con las áreas no cubiertas definidas como «mercado abierto»). Los editores británicos generalmente consideran a los países europeos y a sus antiguas colonias, como India, como sus territorios, mientras que los editores norteamericanos tratan de expandirlos más allá de Norteamérica hacia el Pacífico, como muestra este pasaje de una entrevista con el director de un sello de calidad perteneciente a un gran conglomerado multinacional:

Tenemos una lista de territorios anexados a nuestros contratos, y esto tiene que ver con el mercado abierto, por lo que somos muy cuidadosos en tantear y captar tantos territorios como podamos. Y los editores británicos tradicionalmente tienen todos los territorios que constituían la vieja Mancomunidad Británica de Naciones, cuando Gran Bretaña era un imperio, y Estados Unidos ha tenido que arremeter muy arduamente con esto porque ya no hay imperio, y por qué tendrías automáticamente los derechos para vender en India, India ya no es tu colonia y tampoco lo es Sudáfrica, tampoco lo es Singapur o Malasia o Hong Kong. De hecho, miramos hacia el Pacífico desde California, es más fácil para nosotros comercializar allá... Sí, podes tomar Europa porque está justo cruzando el canal. Pero, ¿por qué no podríamos tomar Asia? Pelearemos también por América del Sur y África y Asia. Así que se trata de un motivo de controversia constante. Lo que me causa risa es que compré un libro de un editor británico y miré su lista de territorios, organizada por continente. Y sorprendentemente, abarcan la Antártida. Es más, «la Antártida Británica». La Antártida está dividida, así que tienen la Antártida Británica entre sus territorios, lo que me hace reír a carcajadas, nunca vi algo así... pero ellos la tienen en su lista de territorios, ni más ni menos, de manera que nosotros, norteamericanos, no creo que podamos vender un libro en la Antártida. Eso es realmente chistoso. (Entrevista, 5 de octubre, 2007) 
Por lo tanto, las consideraciones económicas están involucradas en la producción y en la circulación de libros y, en muchos casos, prevalecen sobre otras. Esto ocurre especialmente en países donde el mercado del libro está liberado. En Estados Unidos y en el Reino Unido, los bienes culturales aparecen principalmente como productos comerciales que deben obedecer la ley de rentabilidad. Esto queda demostrado por el proceso de producción estandarizada de éxitos de venta mundiales tales como Cincuenta sombras de Grey (Illouz). En la era de la globalización, la industria editorial fue progresivamente dominada por los grandes conglomerados que imponen feroces criterios de rentabilidad comercial y funcionamiento en detrimento de los criterios literarios e intelectuales (Bourdieu «Una revolución conservadora»; Schiffrin; Thompson). Esta concentración de la producción está reforzada por la concentración de la distribución alrededor de cadenas tales como Barnes \& Noble, que tienden a centrarse en libros de gran éxito. Por consiguiente, muchos libros ni siquiera son ofrecidos a la venta para minoristas. Este es especialmente el caso de libros traducidos en Estados Unidos debido a la opinión compartida respecto del endeble potencial comercial de la traducción.

Por lo tanto, mientras el desarrollo capitalista de la industria del libro ayuda a liberarlo del control estatal, en Estados Unidos y en el Reino Unido el mercado puede ejercer una censura comercial que es sólo débilmente contrarrestada por las ventas de las librerías independientes y por internet. Aunque la dinámica de la globalización impulsó la industria local del libro en muchos países y fomentó el intercambio cultural a través de la traducción (el número de traducciones en el mundo se incrementó en un 50 \% entre 1980 y 2000 de acuerdo al Index Translationum), el proceso de concentración ha tenido un impacto negativo sobre la diversidad cultural (Sapiro «Globalization»); el porcentaje de traducciones del inglés en el mundo creció de un $45 \%$ en los años ochenta a un $59 \%$ en los noventa, según la misma fuente. Al mismo tiempo, el porcentaje de traducciones en Estados Unidos y en el Reino Unido fue la más baja del mundo: alrededor del $3 \%$.

Para posicionar a las traducciones en el campo de la edición, necesitamos entender su estructura, polarizada entre un polo de gran producción y un polo de producción restringida (Bourdieu Field of Cultural Production; Bourdieu «Una revolución conservadora»): el polo de gran producción está regulado por la ley de rentabilidad a corto plazo (representado por los libros de gran éxito), mientras que en el polo de producción restringida las lógicas específicas y los valores de los campos de producción cultural, en nuestro caso, el campo literario, prevalecen sobre las consideraciones comerciales. Esta polarización también estructura el mercado mundial de las traducciones (Sapiro «Translation and the Field»).

Las traducciones del inglés dominan los géneros comerciales (como los thrillers y las novelas románticas) y los destinados al mercado masivo donde la diversidad lingüística es muy baja. Más aún, las obras traducidas del inglés muchas veces compiten en este sector con la producción de libros en su lengua original que se desarrolló tardíamente. La circulación global de estos productos del mercado masivo es fomentada, por un lado, por conglomerados transnacionales y, por el otro, por la propensión de los editores de diferentes países a imitarse mutuamente, es decir, a adquirir los derechos de libros que fueron previamente vendidos en otro país - siendo la imitación uno de los procesos que explican el fenómeno del isomorfismo en los mercados (aquí, el mercado global del libro; sobre el isomorfismo en la edición, ver Franssen y Kuipers).

Esta observación también nos ayuda a explicar por qué el porcentaje de traducciones es tan débil en la producción del libro norteamericana y británica: dado que son consideradas poco 
rentables, circulan muy pocas traducciones en el polo de gran producción del campo editorial. Por el contrario, el polo de producción restringida es mucho más diversificado respecto de las lenguas originales de las que provienen los libros que se traducen, y esto es especialmente cierto en literatura que constituye la más diversificada categoría de libros: en Francia, por ejemplo, las traducciones acaparan más de un tercio de los nuevos títulos literarios y provienen de más de treinta y seis lenguas y de cuarenta países. Sin embargo, las coacciones comerciales también tienen cada vez más impacto en el polo de producción restringida, especialmente en los Estados Unidos y en el Reino Unido, más allá de los esfuerzos activos de pequeños editores independientes en la promoción de lo que llaman «literatura internacional» (Sapiro «Globalization»).

\section{Factores culturales}

La práctica de la traducción precedió la emergencia del mercado del libro y contribuyó a su desarrollo. En términos históricos, el primer bestseller traducido fue la Biblia: impresa por primera vez en 1455, continúa siendo hoy el texto más traducido (con alrededor de 400 traducciones completas y 2300 parciales). La amplia difusión de este texto sagrado en diferentes lenguas estuvo determinada por factores religiosos así como por las lógicas del mercado emergente. Sin embargo, se encontraban traducciones de la Biblia antes de que circulara en forma impresa, y fue una cuestión central en las luchas que constituyeron el campo religioso.

La traducción también desempeñó un papel crucial en la formación de los campos literario y editorial. Mediante la constitución de un corpus de textos, contribuyó a la estandarización de los lenguajes nacionales, en algunos casos, mucho antes de que se desarrollara una producción autóctona de textos en estos lenguajes. La traducción también proporcionó recursos literarios y modelos para la escritura de la ficción contemporánea (Even-Zohar:45-52). Este proceso subraya lo que Franco Moretti ha denominado la «ley Jameson»: siguiendo los análisis de Fredric Jameson sobre las novelas japonesas e indias como híbridos de formas occidentales y realidades locales «en culturas que pertenecen a la periferia del sistema literario (es decir: casi todas las culturas, dentro o fuera de Europa), la novela moderna surge no como un desarrollo autónomo sino como un compromiso entre una influencia formal occidental (por lo general, francesa o inglesa) y materiales locales» (Moretti:163). Las obras más traducidas constituyeron el nuevo canon de la literatura mundial (Casanova). Este canon de literatura moderna en lenguas vernáculas sustituyó progresivamente al canon greco-latino clásico, que continuó siendo dominante en el mercado mundial de la traducción hasta la Segunda Guerra Mundial (Milo). Autores como Esquilo, Sófocles, Eurípides, Horacio, Plutarco, Séneca, Plauto y Tácito, que estaban entre los sesenta más traducidos hacia el comienzo de los años treinta, según el Index Translationum, desaparecieron de la lista después de la Segunda Guerra Mundial; Platón fue el único que sobrevivió. Fueron reemplazados por Tolstoi, Dickens, Dostoievski y Balzac, por citar sólo los más estables en la lista de los treinta escritores más traducidos.

El nuevo canon estaba circunscripto a la literatura europea, además de unas pocas excepciones tales como Rabindranath Tagore, escritor indio ganador del Premio Nobel. En los años cincuenta, la UNESCO lanzó un programa de apoyo a las traducciones provenientes de culturas no occidentales con el objetivo de catalizar la «interpenetración literaria». Este programa animó a editores y a editoriales a iniciar la traducción de obras clásicas y modernas provenientes de Asia y de América Latina, expandiendo los límites del mercado internacional de las traducciones 
de Europa al mundo (aunque áreas completas como el África subsahariana estuvieron y están todavía excluidas de este mercado). Por ejemplo, en Francia el sinólogo René Étiemble creó en 1953 la colección titulada "Conocimiento del oriente». Aunque la China comunista no estaba incluida en los proyectos de la UNESCO, Étiemble persuadió al director de Gallimard respecto de la necesidad de traducir autores chinos modernos tales como Lu Xun en función de avalar la «revolución literaria» que se había producido en el país cuarenta años atrás. Como le explicó a Roger Caillois, responsable del programa de la UNESCO, en una carta fechada el 5 de julio de 1953, su propósito era volver

accesible al educado público francés obras de alta calidad literaria que nunca se habían publicado en nuestra lengua (o mal traducidas, por lo que es mejor no hablar de ellas), y elegidas con el fin de ilustrar las costumbres y valores culturales en todos los países en cuestión: India, China y Japón, para empezar (pero me gustaría incluir a Persia y al mundo árabe).

Ni el editor ni yo buscamos éxito comercial inmediato: queremos formar al público, revelarles el Oriente. Demás está decir que tendremos, especialmente al principio, que ofrecerles títulos que los animen a formarse por sí mismos: novelas que, sin dejar de entretenerlos, los pongan al corriente sobre pueblos con los que no están familiarizados. La mayoría de las grandes novelas asiáticas son desconocidas en Francia. (Archivos Gallimard; mi traducción)

Esta carta hace hincapié en la función pedagógica atribuida a las traducciones de la literatura extranjera de calidad, especialmente a aquellas publicadas en regiones periféricas. La convicción de que la literatura puede informarnos respecto de la cultura y de las costumbres de un país, que también sustenta la enseñanza de lenguas extranjeras y civilización en Francia como en otros lugares, ayuda a explicar el alza de traducciones de ciertas lenguas periféricas. Más allá de la duración y del alcance de la iniciativa —la gran novela china Hong Leou Meng sumaba 2500 páginasdiez títulos se han publicado en estas colecciones hacia 1960.Si, como era de esperar, las ventas fueron modestas (1189 copias, en promedio), aun así, la colección llenó un vacío en la edición y la cultura francesas, y fue, por eso, muy elogiada por los críticos.

Esta colección ilustra la lógica específica de los campos culturales que ganan autonomía respecto de las constricciones políticas y económicas (Bourdieu Las reglas del arte). Esta lógica es irreductible a las motivaciones ideológicas o financieras. Muchos autores, traductores, editores e incluso editoriales desarrollan proyectos que saben, no les traerán ningún beneficio comercial, como lo ejemplifica la cita de Étiemble. En cambio, pueden esperar beneficios simbólicos tales como el reconocimiento en el campo.

Importar una obra literaria de un campo nacional a otro implica que será recibida fuera de su contexto de creación, abriendo un amplio espacio para la interpretación y para estrategias de apropiación a través de la clasificación, los prefacios, las críticas, etc., que pueden ser entendidas sólo a la luz de las cuestiones específicas en juego en el campo de recepción (Bourdieu «Las condiciones sociales»; Damrosch). Pero el aspecto más importante del proceso de recepción para la historia literaria es, probablemente, la apropiación de obras extranjeras como modelos para el desarrollo de nuevas técnicas narrativas y para subvertir las normas literarias dominantes: Faulkner y John Dos Passos fueron tales fuentes para Jean-Paul Sartre (para ejemplos más detallados de este tipo de apropiación, ver Casanova). 


\section{Factores sociales}

Los factores culturales en juego en la circulación de las obras literarias están insertos en relaciones de poder entre grupos sociales. Durante mucho tiempo, el canon de las obras literarias estuvo compuesto principalmente por autores blancos, varones y occidentales. Como hemos visto, se ha empezado a extender a las culturas no occidentales en los años cincuenta, gracias a la política voluntaria configurada por la UNESCO. Los autores de Asia y de América Latina comenzaron a obtener reconocimiento internacional en los sesenta y setenta. Los premios literarios son un buen indicador de este reconocimiento. Si consideramos el premio internacional más prestigioso, el Nobel, tenemos que fue otorgado a Miguel Ángel Asturias en 1967, Yasunari Kawabata en 1968, Pablo Neruda en 1971 y Gabriel García Márquez en 1982. El único escritor árabe que lo ha ganado fue, hasta la fecha, Naguib Mahfouz en 1988. El proceso de reconocimiento le llevó aún más tiempo a los autores poscoloniales que han tenido que desarrollar estrategias específicas para llamar la atención (Huggan; Brouilllette; Moudileno). No fue sino hasta los ochenta que los autores africanos comenzaron a hacerse visibles en la escena literaria internacional; Wole Soyinka, por ejemplo, recibió el Premio Nobel en 1986. En 1987, por primera vez, un autor árabe francófono, Tahar Ben Jelloun, ganó el Premio Goncourt y se convirtió en uno de los escritores más traducidos del francés en Estados Unidos entre 1990 y 2003 con seis títulos (para el acceso al mercado global de los escritores magrebíes poscoloniales, ver Lewis).

La consagración de escritores poscoloniales contribuyó a relativizar las categorías nacionales en la percepción de las obras literarias: aunque las autoridades literarias nacionales y, por consiguiente, internacionales, tendieron a promocionar a autores «nacionales» - aquellos que habían estado arraigados por más de dos generaciones en el país, que habían vivido en los centros culturales y que provenían de las clases medias o altas-, un creciente interés en escritores antes relegados a los márgenes por sus orígenes geográfico o étnico comenzaron a tomar relevancia alrededor de 1992. Ese año, el poeta oriundo de Santa Lucía, Derek Walcott, fue galardonado con el Premio Nobel; el novelista canadiense nacido en Sri Lanka, Michael Ondaatije, con el Booker y el francés radicado en Martinica, Patrick Chamoiseau, el Goncourt. En Francia, la noción misma de «literatura mundial» alcanzó un significado específico en un manifiesto titulado «Por una literatura mundial en francés». Firmado por 44 autores y publicado en Le Monde el 15 de marzo de 2007 por Jean Rouaud y Michel Le Bris, dicho manifiesto distinguía a los escritores periféricos, poscoloniales, progresistas y emigrados de aquellos escritores parisinos bien establecidos, acusando a los últimos de estar desconectados del mundo desde una postura narcisista. Mientras el manifiesto suscitaba un debate internacional entre especialistas de los estudios franceses y francófonos (ver, por ejemplo, Miller), la editorial Gallimard publicó una colección de ensayos sobre la cuestión. Sin embargo, como ha señalado Ducourneau, la mayoría de quienes firmaron el manifiesto habían publicado en París, en muchos casos con el prestigioso editor Gallimard que aseguraba su visibilidad en los mercados literarios franceses e internacionales. De hecho, como ya hemos visto, la centralidad y la marginalidad están condicionadas por los medios de producción.

Las mujeres también fueron marginadas por las autoridades literarias, si bien muchas habían dinamizado el campo literario y el mercado desde el siglo XIX. En Francia, el premio Goncourt, creado en 1902, fue adjudicado por primera vez a una mujer, Elsa Triolet, en 1945. En protesta contra la misoginia alrededor del Goncourt, un grupo de 22 escritoras mujeres crearon en 1994 el premio Femina que puede concederse tanto a autores mujeres como varones. En cuanto a la 
Academia francesa, Marguerite Yourcenar fue la primera mujer incorporada a sus filas en 1982, uno año antes de la elección del senegalés Léopold Sédar Senghor como uno de sus miembros. En el mercado mundial de las traducciones, las escritoras están aún poco representadas: sólo un cuarto de las obras literarias traducidas del francés en Estados Unidos entre 1990 y 2003 y sólo un tercio de los títulos de la literatura contemporánea llevan la firma de una mujer (Sapiro «Symbolic Capital»). Por no hablar de la consagración de mujeres por el Premio Nobel: se cuentan 12 mujeres entre 114 ganadores, es decir, menos del $10 \%$. El avance resultó significativo a partir de los años noventa con siete mujeres que lo han obtenido desde entonces - Nadine Gordimer, Toni Morrison, Elfriede Jelinek, Doris Lessing, Herta Müller, Alice Munro y Svetlana Alexievich — frente a sólo cinco durante los primeros noventa años del siglo XX: Selma Lagerlöf, Grazia Deledda, Sigrid Undset, Gabriela Mistral, Nelly Sachs (con Shaï Agnon).

Tras su globalización, desde los años sesenta en adelante, observamos, de este modo, una feminización del canon literario mundial, en paralelo con la inclusión de autores poscoloniales. No obstante, todos estos autores se publican en los centros del mercado literario global y sus textos, escritos en lenguas centrales, tienen aún más posibilidades de obtener reconocimiento internacional que aquellos escritos en lenguas periféricas.

\section{Conclusión}

Poco después del reemplazo del canon clásico por el moderno, hacia finales de los años 50, el número de autores no canonizados entre los escritores más traducidos se incrementó considerablemente debido a la popularidad de los thrillers (como los de Agatha Christie y Peter Cheney) y alrededor de 1970 esos autores comenzaron a superar el número decreciente de autores reconocidos (Milo). Este crecimiento indica que la demanda del mercado ha sobrepasado las jerarquías educativas y culturales. Sin embargo, mientras el porcentaje de autores consagrados internacionalmente (es decir, ganadores de premios literarios) en las listas de éxitos de venta en Estados Unidos cayó del 5 \% en los años setenta al $1 \%$ en los noventa, su presencia creció en Francia y en Alemania durante el mismo período (Verboord). Así, la lógica del mercado no se propaga de modo homogéneo.

Moretti distingue dos modelos de evolución, ondas y árboles. Estos dos modelos se utilizan para la historia de la literatura y pueden explicarse por dos procesos opuestos: isomorfismo y diferenciación. Tal como lo analizó la teoría sociológica neo-institucional, el isomorfismo se deriva de tres tipos de mecanismos: coacción, imitación y normas profesionales (Di Maggio y Powell). Estos mecanismos son aplicables para las condiciones de producción de bienes culturales. La coacción actúa como el principal instrumento homogeneizante en los regímenes autoritarios: el canon del realismo socialista fue en gran medida impuesto por la URSS a otros regímenes comunistas. La imitación es típica del libre mercado competitivo. Los editores darán preferencia a obras ya seleccionadas por otros pares en otros países a los efectos de reducir la incertidumbre (Franssen y Kuipers). Las normas profesionales se propagan alrededor del mundo a través de organizaciones profesionales tales como la unión internacional de editores que está vinculada con los sindicatos de editores nacionales o el PEN Club que tiene centros locales en diferentes países. Los agentes literarios también contribuyen a unificar las normas profesionales de los campos nacionales de la edición. Estas normas pueden variar dentro del campo de la edición entre los polos de gran producción y los de producción restringida; por ejemplo, la fidelidad al original y la traducción directa, dos normas generalizadas en la edición de calidad, no se aplican para los géneros más comerciales. 
Las normas de la edición de calidad se derivan claramente de los campos literario y académico donde la originalidad ha sido un valor central desde el período romántico. La originalidad es un principio de diferenciación que contrarresta la tendencia al isomorfismo en las industrias creativas. El principio de originalidad rige no sólo el trabajo del productor cultural, reconocido como un creador también para la edición: el editor literario tiene una «identidad» y funciona como una «marca registrada» que clasifica cierto tipo de productos; por ejemplo, algunos editores desempeñaron un rol importante en la reunión de grupos literarios tales como el noveau-roman alrededor de Éditions de Minuit. La importancia de la marca registrada de los editores en el mercado mundial está ligada a su capital simbólico, es decir, a sus autores de renombre, ganadores de Premio Nobel, etc. La imitación no se produce ni mecánica ni aleatoriamente. Los editores tienden a seguir las elecciones de ciertos pares extranjeros más que otros. Las afinidades electivas expresan identidades y, por ende, distinción (Bourdieu La distinción). El principio de distinción también se aplica a los Estados-nación que pretenden tener, todos, una literatura nacional. La importancia concedida durante mucho tiempo a lo nacional como categoría de clasificación literaria, a pesar del proceso de globalización, la emergencia de las corporaciones multinacionales y el creciente isomorfismo en el polo de gran producción del campo de la edición transnacional es revelador de esta lógica de diferenciación. Diferenciación que también cae sobre el «exotismo poscolonial» definido por Graham Huggan como la «espectacularización' global de las diferencias culturales» (Huggan 15). Finalmente la apropiación que nunca es mecánica y que no puede reducirse al mimetismo, también introduce diferenciación a través de la hibridación de géneros y de tradiciones culturales (Appadurai; Venuti 159). Mientras los mecanismos que favorecen el isomorfismo se traducen en ondas homogeneizantes, el proceso de diferenciación provoca ramificaciones que forman árboles. Abrumado por el mercado masivo, el polo de producción restringida constantemente resurge y extiende sus ramificaciones.

\section{Notas}

1 Agradecemos al Journal of World Literature (en especial a su director, David Damrosch) así como a la editorial Brill la autorización para traducir «How Do Literary Works Cross Borders (or artículo que publicamos sin modificaciones, incluso de normas de edición respecto de su versión original, se incluyó en el número 1 de la revista editada en 2016 (81-96).

Not)?» de Gisèle Sapiro y luego, para ponerlo en circulación. Este

\section{Obras citadas}

Appadurai, Arjun. Modernity At Large: Cultural Dimensions of Globalization. Minneapolis, MN: University of Minnesota Press, 1996.

Apter, Emily. Against World Literature: On the Politics of Untranslatability. London: Verso. 2013.

Bourdieu, Pierre. Distinction: A Social Critique of the Judgement of Taste, trad. de R. Nice, Cambridge, MA:

Harvard University Press, 1984 [1979]. [en español: La distinción. Criterios y bases sociales del gusto, trad. de María del Carmen Ruiz, Madrid, Taurus, 1998].

Bourdieu, Pierre. The Field of Cultural Production: Essays on Art and Literature, ed. de R. Johnson, Cambridge: Polity Press, 1993.

Bourdieu, Pierre. The Rules of Art: Genesis and Structure of the Literary Field, trad. de Susan Emanuel.

Cambridge-Stanford: Polity Press-Stanford University Press, 1996 [1992]. [en español: Las reglas del arte. Génesis y estructura del campo literario, trad. de Thomas Kauf, Barcelona, Anagrama, 1995]. 
Bourdieu, Pierre. «The Social Conditions of the International Circulation of Ideas.» En Bourdieu: A Critical Reader, ed. Richard Shusterman. Oxford and Malden: Wiley- Blackwell, 1999 [1989], 220-228. [en español: «Las condiciones sociales de la circulación de las ideas», en Intelectuales, política y poder, trad. de Alicia Gutiérrez, Buenos Aires, Eudeba, 1999, 159-170].

Bourdieu, Pierre. «A Conservative Revolution in Publishing», trad.de Ryan Fraser, Translation Studies 1:2 (2008 [1999]), 123-153. [en español: «Una revolución conservadora en la edición», en Intelectuales, política y poder, trad. de Alicia Gutiérrez, Buenos Aires, Eudeba, 1999, 223-267].

Brouillette, Sarah. Postcolonial Writers and the Global Literary Marketplace. New York: Palgrave Macmillan, 2007. Casanova, Pascale. The World Republic of Letters, trad. de M.B. De Bevoise. Cambridge, MA: Harvard University Press, 2004 [1999].

Damrosch, David. What is World Literature? Princeton, NJ: Princeton University Press, 2003.

DiMaggio, Paul J. y Powell, Walter W. «The Iron Cage Revisited: Institutional Isomor- phism and Collective Rationality in Organizational Fields.» American Sociological Review 48 (1983), 147-60.

Ducournau, Claire. La fabrique des classiques africaines. Écrivains d`Afrique subsaharienne francophone. Paris: CNRS Éditions, 2017.

Even-Zohar, Itamar. «Polysystem Studies.» Poetics Today 11:1 (1990).

Franssen, Thomas y Giselinde Kuipers. «Coping with Uncertainty, Abundance and Strife: Decision-Making Processes of Dutch Acquisition Editors in the Global Market for Translations.» Poetics 41:1 (2013), 48-74. Heilbron, Johan. «Towards a Sociology of Translation: Book Translations as a Cultural World System.» European Journal of Social Theory 2:4 (1999), 429-444.

Heilbron, Johan y Sapiro, Gisèle. «Outline for a Sociology of Translation: Current Issues and Future Prospects.» En Constructing a Sociology of Translation, eds. Michaela Wolf and Alexandra Fukari, Amsterdam: John Benjamins, 2007, 93-108.

Huggan, Graham. The Postcolonial Exotic: Marketing the Margins. London: Routledge, 2001.

Illouz, Eva. Hard-Core Romance: «Fifty Shades of Grey,» Best-Sellers, and Society. Chicago, IL: University of Chicago Press, 2014.

Jacquemond, Richard. «Translation Policies in the Arab World. Representations, Dis-courses, Realities.» The Translator 15:1 (2009), 1-21.

Lewis, Mary Anne. The Maghreb Goes Abroad: The «Worlding» of Postcolonial North African Francophone Literature and Film in a Global Market. Tesis doctoral, Yale University, 2013.

Loiseaux, Gérard. La Littérature de la défaite et de la collaboration, d' après «Phonixoder Asche?» de Bernhard Payr. Paris: Fayard, 1995.

Miller, Christopher. «The Theory and Pedagogy of a World Literature in French.» Yale French Studies 120 (2011), 33-48.

Milo, Daniel. «La bourse mondiale de la traduction: un baromètre culturel.» Annales 1 (1984), 92-115.

Moretti, Franco. «Conjectures on World Literature,» New Left Review 1 (January-February 2000), 1-12; reimpreso en David Damrosch, ed., World Literature in Theory. Oxford: Wiley-Blackwell, 2014.

Moudileno, Lydie. «Fame, Celebrity, and the Conditions of Visibility of the Postcolonial Writer.» Yale French Studies 120 (2011), 62-74.

Pinhas, Luc. Éditer dans l' espace francophone: législation, diffusion, distribution et commercialisation du livre. Paris: Alliance des éditeurs indépendants, 2005.

Perucca, Brigitte. «La France règne en maître sur le marché des manuels scolaires en Afrique francophone». Le Monde, 10 de junio de 2010. 
Popa, Ioana. Traduire sous contraintes. Littérature et communisme. Paris: CNRS Éditions, 2010.

Rundle, Christopher. Publishing Translations in Fascist Italy. Oxford: Peter Lang, 2010.

Sapiro, Gisèle. «The Literary Field between the State and the Market.» Poetics 31:5-6 (2003), 441-461.

Sapiro, Gisèle. «Translation and the Field of Publishing.A Commentary on Pierre Bourdieu's 'A Conservative Revolution in Publishing' from a Translation Perspective.» Translation Studies 1:2 (2008), 154-167.

Sapiro, Gisèle. «Globalization and Cultural Diversity in the Book Market: The Case of Translations in the US and in France.» Poetics 38:4 (2010), 419-39.

Sapiro, Gisèle. «Strategies of Importation of Foreign Literature in France in the Twentieth Century: The Case of Gallimard, or the Making of an International Publisher.» En Institutions of World Literature: Writing, Translation, Markets, eds. Stefan Helgesson and Pieter Vermeulen. London: Routledge, 2015, 143-159.

Sapiro, Gisèle. «Translation and Symbolic Capital in the Era of Globalization: French Literature in the United States.» Cultural Sociology 9:3 (2015), 320-346.

Sapiro, Gisèle, ed. Translatio. Le marché de la traduction en France à l'heure de la mondialisation. Paris: CNRS Éditions, 2008.

Schiffrin, André. The Business of Books. Verso, New York, 2000.

Tarde, Gabriel. The Laws of Imitation. New York, NY: Henry Holt, 1903 [189o]. Thompson, John B. Merchants of Culture: The Publishing Business in the Twenty-First Century. Cambridge: Polity Press, 2010.

Thomson-Wohlgemuth, Gaby. Translation under State Control: Books for Young People in the German Democratic Republic. New York and London: Routledge, 2009.

Venuti, Lawrence. The Scandals of Translation.Towards an Ethics of Difference. New York/London: Routledge, 1998. Verboord, Marc. «Market Logic and Cultural Consecration in French, German and American Bestseller lists, 1970-2007.» Poetics 39:4 (2011), 290-315. 